\title{
Civicae
}

\section{Uma visão sobre a ética moral na perspectiva de Agostinho de Hipona e Tomás de Aquino}

Os filósofos Gregos, como Sócrates, Platão e Aristóteles muito contribuíram na interpretação e análise do comportamento humano e seu modo agir. A partir desse período muitos outros pensadores também se revestiram de discussões éticas para explicarem e compreenderem a realidade, a moral e a organização social. Nesse contexto dois filósofos medievais se destacaram com seus pensamentos acerca da ética: Agostinho de Hipona e Tomás de Aquino que abordam as virtudes como elementos essenciais à conduta humana. Esta pesquisa foi realizada através de uma revisão bibliográfica de caráter discursivo abordando a ética moral.

Palavras-chave: Ética; Moral; Agostinho de Hipona; Tomás de Aquino.

\section{A view on moral ethics from the perspective of Augustine of Hippo and Thomas Aquinas}

Greek philosophers such as Socrates, Plato, and Aristotle greatly contributed in the interpretation and analysis of human behavior and its way of acting. Since that time many other thinkers have also clothed themselves in ethical discussions to explain and understand reality, morality, and social organization. In this context two medieval philosophers stood out with their thoughts on ethics: Augustine of Hippo and Thomas Aquinas that approach the virtues as essential elements to the human conduct. This research was carried out through a bibliographical review of a discursive character addressing moral ethics.

Keywords: Ethic; Moral; Augustine of Hippo; Thomas Aquinas.

Topic: Ética

Reviewed anonymously in the process of blind peer.
Received: 04/03/2019

Approved: 22/05/2019
Tayronne de Almeida Rodrigues (iD)

Faculdade de Juazeiro do Norte, Brasil

http://lattes.cnpq.br/8602100500602426

http://orcid.org/0000-0001-9378-1456

tayronnealmeid@gmail.com

João Leandro Neto (iD)

Faculdade Entre Rios do Piauí, Brasil

http://lattes.cnpq.br/0489242460344918

http://orcid.org/0000-0003-1738-1164

joaoleandro@gmail.com

Aluísio Vasconcelos de Carvalho (iD

Faculdade Guaraí, Brasil

http://lattes.cnpq.br/5200758055263996

http://orcid.org/0000-0002-3793-3133

aluisiovasconcelos@gmail.com
Tainnã de Almeida Rodrigues Carvalho (iD)

Centro Universitário Doutor Leão Sampaio, Brasil

http://lattes.cnpq.br/8106605310169257

http://orcid.org/0000-0001-6712-1438

tainnaetiago@gmail.com
Referencing this:

RODRIGUES, T. A.; LEANDRO NETO, J.; CARVALHO, A. V.; CARVALHO, T. A. R.. Uma visão sobre a ética moral na perspectiva de Agostinho de Hipona e Tomás de Aquino. Civicae, v.1, n.1, p.8-16, 2019. DOI: http://doi.org/10.6008/CBPC2674-6646.2019.001.0002

DOI: 10.6008/CBPC2674-6646.2019.001.0002 


\section{INTRODUÇÃO}

Ética é o sábio estudo do comportamento humano. Estudar Ética significa reverenciar toda a compreensão da conduta humana, a qual deve ser respaldada pelos valores e pelos princípios norteadores da moral. A Ética estuda os paradigmas que surgem no próprio convívio social, no lugar onde o homem está inserido. A mesma, através do olhar dos filósofos, pensadores capazes de analisar a ação humana, aponta soluções para: uma boa vida, uma plena felicidade e à realização do homem.

Diante de tantos problemas que emergem na sociedade, a Ética surge como uma solução para nortear como resolvê-los. Nos faz refletir as nossas ações, impulsionando-nos à análise do próprio agir, fazendo com que visualizemos melhor os caminhos a serem seguidos, pela liberdade, colaborando nas decisões a serem tomadas.

Neste trabalho objetiva-se a partir de uma discussão teórica que a questão referida não é tão nova quanto se pode pensar, mas remonta desde os primórdios da experiência filosófica encontrada no ser humano. A questão Ética remonta desde a Grécia Antiga, como também do Período Medieval, o qual será tratado a seguir precisamente através da ética agostiniana e tomista. A metodologia abordada é a pesquisa bibliográfica que segundo Gil (2008) é feita sob consulta de materiais existentes sobre determinado assunto, tendo como prioridade livros e artigos científicos.

\section{DISCUSSÃO TEÓRICA}

\section{Agostinho de Hipona}

Nascido em 354, na cidade de Tagaste na Numidia, província romana no norte da África, hoje localizada na Argélia. Faleceu em uma cidade próxima de Hipona, em 430, durante a invasão dessa região por Vândalos liderados por Genserico.

Tendo mãe cristã e pai pagão, Agostinho, viveu toda sua vida durante um período em que o Império Romano já estava em fase de decadência. Tornou-se mestre em retórica na cidade de Cartago, e segundo ele mesmo narra em sua obra Confissões, que foi a leitura do diálogo de Cícero Hortensius, hoje perdido, que despertou seu interesse pela filosofia. Em 387, foi batizado por Ambrósio, bispo de Milão e em 395, foi eleito bispo de Hipona. Uma interessante súmula sobre a vida de Agostinho é encontrada nas obras filosóficas de Battista Mondin.

Agostinho nasceu em Tagaste, em 354, de mãe cristã e pai ainda pagão que recebeu o batismo em 371, pouco antes de morrer. A primeira educação de Agostinho foi estritamente humanística, feita de gramática e retórica. Tendo iniciado os estudos em Tagaste, foi completá-los em Cartago, onde depois da leitura de Hortênsio (uma introdução à Filosofia) de Cícero, começou a interessar-se também pela filosofia. Em Cartago, a filosofia então dominante era a maniquéia; Agostinho não tardou em fazer-se ardoroso defensor deste sistema, com grande desgosto para sua mãe. Aos dezenove anos começou a ensinar retórica em Cartago, rodeado por um grupo de discípulos inteligentes e por muitos amigos, mas também por alunos indisciplinados. O comportamento destes e o desejo de fama moveram Agostinho a transferir-se para Roma. Assim, depois de dez anos de ensino em Cartago, deixou a cidade (em 383) e foi para Roma. (MONDIN, 2013) 
Segundo Neri (2004), Aurélio Agostinho foi sem dúvida um dos filósofos mais importantes do cristianismo, devido a sua criatividade e originalidade, a surgir no pensamento antigo desde Platão e Aristóteles. Foi um filosofo e pensador do final do período antigo, ainda profundamente ligado ao pensamento clássico, mas já refletindo sua própria visão do mundo, prenunciando o papel do cristianismo na formação da cultura ocidental.

Agostinho foi responsável por ser pioneiro ao realizar a grande síntese entre o pensamento Cristão e a filosofia grega. Aderiu ao Maniqueísmo ${ }^{1}$ e depois foi seu crítico e combatente. Em 386, converteu-se ao Cristianismo tendo escrito várias obras, dentre as quais os Acadêmicos de Cícero, defendendo a possibilidade do conhecimento pela verdade revelada.

A filosofia de Agostinho surge baseada no neoplatonismo de Porfírio e Plotino e os ensinamentos de Paulo de Tarso e do evangelho de João. Em seu tratado acerca da doutrina cristã, reforça que a filosofia antiga é para a alma um estágio preparatório; porém, a sabedora humana tem suas limitações, sendo necessário, portanto acreditar em primeiro para depois compreender, segundo os princípios religiosos.

Para Agostinho, a verdadeira e legitima ciência é a teologia e é a seus ensinamentos que o homem deve dedicar-se, pois preparam a alma para a salvação e para a visão de Deus. Agostinho pergunta "como pode a mente humana mutável e falível atingir uma verdade eterna, com certeza infalível". A sua resposta a essa pergunta se baseia na teoria platônica da reminiscência. O diálogo De Magistro, (sob o mestre, c.389) permite boa compreensão do filósofo a este respeito, pois discute "o que é a virtude e se esta pode ser ensinada".

Para Platão "a virtude não pode ser ensinada, ou já a trazemos conosco, ou nenhum mestre será capaz de introduzi-la em nossa alma, uma vez que é uma característica da própria natureza humana". Agostinho começa neste texto, justamente se interrogando sobre o que é ensinar e apreender. Não aceita, entretanto, a doutrina platônica da reminiscência, mas desenvolve sua teoria da interioridade e da iluminação como uma resposta que considera mais completa para essa questão.

Agostinho segundo a tradição cristã, foi o primeiro pensador a desenvolver, segundo Nunes (2011) com base em concepções neoplatônicas e estoicas, uma noção de interioridade que prenuncia o conceito de subjetividade do pensamento moderno. Encontra-se já formulada em seu pensamento a oposição interiorexterior e a concepção de que a interioridade é o lugar da verdade. É olhando para sua interioridade que o homem descobre a verdade, sendo este o sentido da célebre fórmula in interiore homine habitat veritas ${ }^{2}$.

Nesta concepção, Agostinho, desenvolve sua obra histórica baseando-se em que os fatos ocorridos devem injetar no homem de fé um ânimo para viver o seu tempo, pois a própria história mostra um processo sucessivo de alianças e rupturas entre o Homem e seu Criador. Afinal, tendo sido o homem criado a imagem e semelhança de Deus, a mente humana possui uma centelha do intelecto divino. Nesse contexto Agostinho

\footnotetext{
${ }^{1}$ Religião fundada por Mani no século III como um desdobramento do cristianismo, que apresentava uma visão dualista do mundo, em luta eterna do Bem contra o Mal.

2 "No homem interior habita a verdade". 
deixa a lição que todos os acontecimentos históricos devem ser interpretados à luz da revelação: tudo prepara para a redenção e o juízo final, quando, só então a "cidade celestial" triunfará definitivamente.

É neste contexto, que a teoria da natureza humana e da iluminação divina foram fundamentais para a consolidação das doutrinas cristãs nesse período e na Idade Média, dada sua importância e influência como teólogo e filosofo. Havia uma preocupação em tornar cristãos os bárbaros pagãos, afinal, eram dotados da mesma natureza humana ao invés de simplesmente combatê-los já que não havia condições de derrotá-los pelas armas. Ocorreu então, a cristianização da Europa ocidental naquele momento de profundas mudanças.

\section{A busca da Verdade}

Conforme Pérez (1988), a filosofia agostiniana é uma devotada procura da verdade, que tem seu ápice na verdade, que é Cristo. É um movimento incessante, uma paixão e precisamente a paixão principal: o amor.

Essa "passionalidade" da filosofia agostiniana não é em nenhum momento de irracionalismo ou voluntarismo. Se incita a ter fé para entender, também anima a entender para crer melhor. Nada nos pode fazer duvidar da possibilidade de chegar à verdade. Nada valem os argumentos céticos. Si fallor, sum: "se me engano, é uma prova de que sou", diz, antecipando-se, num contexto muito diferente, a Descartes. E com mais clareza: "Sabes que pensas? Sei. Ergo verum est cogitare te, logo é verdade que pensas". (PÉREZ, 1988)

Diz Agostinho: "Não queiras sair para fora; é no interior do homem que habita a verdade". E há verdades constantes, inalteráveis, para sempre. Dois mais dois serão sempre quatro. Agostinho tenta esclarecer de onde pode vir essa verdade. Não das sensações, diz ele, porque essas são e não são, são mutáveis, efêmeras. Tampouco do espírito humano que por mais profundo que seja, é limitado.

\section{A busca da Alma}

O homem é uma alma que usa um corpo; ou uma alma racional, que se serve de um corpo terrestre e mortal; ou, "uma alma racional que tem um corpo". Tudo indica que para Agostinho, o homem é a alma. E, contudo, há textos que parecem fugir ao platonismo:

Porque o homem não é só corpo ou apenas alma, mas o que é constituído de alma e de corpo. Esta é a verdade: a alma não é todo o homem, mas é a melhor parte do homem; nem todo o homem é o corpo, mas a porção inferior do homem; quando as duas estão juntas, temos o homem. (AGOSTINHO, 1990)

Agostinho supera a desvalorização do aspecto corporal, tão essencial no platonismo e no neoplatonismo. O corpo é matéria, criação de Deus e por isso é bom. Não é o cárcere nem o túmulo da alma.

Fica claro que a alma é imortal, porque conhece as verdades imortais e eternas. Conhecer a verdade nesse sentido para Agostinho é evidente: Como pode morrer ou desaparecer o que é a sede do indestrutível?

A teoria agostiniana estabelece, assim, que todo o conhecimento verdadeiro é o resultado de um processo de iluminação divina, que possibilita ao homem contemplar as ideias, arquétipos externos de toda a realidade. (PESSANHA, 1980)

\section{A Ética Moral para Agostinho}

A ética de Agostinho possui um paradigma claro, ela depende de Deus. Porém ao mesmo tempo ele parte do princípio do pecado original. Essa concepção do pecado de Agostinho não infantiliza o homem, 
porém o trata como um ser que poderá tender tanto ao bem (a Deus) ou ao mal (o pecado). Dessa forma, diferente de outros autores ele não entende que o ser humano é sumariamente bom, como entendia a religião antes do pecado original, mas ele compreende esse ser humano como alguém que, se não seguir uma vida virtuosa em Deus, será levado ao mal ou aos vícios da carne e, por isso, o ser humano não poderá se valer de sua própria natureza para a salvação.

A ética de Agostinho é, pois, uma ética eudemonista e teleológica e a diferença em relação à grega é que a felicidade não consiste em bens do corpo e do espírito ou em ambos, mas no gozo de Deus, que é autêntico sumo bem. Mas como podemos saber o que temos de fazer para atingir a beatitude? A fonte para o conhecimento das normas morais é a luz divina, que nós podemos perceber em nós mesmos, na nossa consciência." (DEMÉTRIO, 2004)

Para Agostinho existem os homens que vivem segundo o espírito e os homens que vivem pela carne. Ele explica que a vida segundo o espírito ou segundo o amor, irá gerar certas virtudes: a prudência, a coragem, a justiça, e a humildade. Em contrapartida a vida segundo a carne gera os vícios: a avareza, a luxúria, e a soberba.

Agostinho apreciou muito dos filósofos pagãos antes de sua conversão e procurou a duras penas conciliar o cabedal ético dos gregos com a moral do cristianismo. Havia um ponto comum a ser explorado: o valor das virtudes. Na obra Confissões, Agostinho tece poesia com filosofia, e filosofa com teologia. Faz declarações de amor a Deus e intui o amor de Deus pelos homens.

Agostinho acentua essa leitura da mensagem de Cristo como ética do amor e não da lei. Não basta agir segundo a lei, mas é preciso assim proceder com a intenção adequada, que deve ser a do amor de Deus e do desejo de se aperfeiçoar para se aproximar cada vez mais dele. Mas quanto ao fato de o homem atingir ou não o objetivo da salvação e da beatitude eterna, não depende dos méritos que ele possa conquistar com a conduta correta, depende exclusivamente da graça divina." (DEMÉTRIO, 2004)

O problema do mal e do livre-arbítrio suscita, pois, no horizonte da reflexão sobre a ideia da ordem e da beatitude, a questão fundamental sobre o fim objetivo último da ordem, que é igualmente seu princípio: a questão de Deus. Como tal, Deus é necessariamente o objeto supremo da beatitude e é nessa supremacia absoluta que é dado a conhecer pela mediação cristológica, cuja ausência é, segundo Agostinho, a grande e insanável falha da ascensão neoplatônica, que a metafísica da ordem e o seu prolongamento ético na doutrina da beatitude encontram o fundamento último.

\section{Tomás de Aquino}

Tomás de Aquino foi certamente um grande teólogo do catolicismo romano. Recebeu os títulos de Doutor Angélico, Doutor Comum, Doutor Universal. Nascido em 1225 no castelo pertencente a seu pai, em Aquino, um condado localizado em Roccasecca, no reino da Sicília (hoje Lácio). Tomás começou suas instruções na abadia de Monte Cassino e posteriormente estudou na Universidade de Nápoles.

O século XIII é celebrado por todos os estudiosos como o século de ouro da Idade Média. É nele, com efeito, que a civilização medieval atinge pontos culminantes em todos os campos: nas artes, na literatura, na política, na teologia e também na filosofia. O que distingue o gênio dos homens deste tempo é o perfeito equilíbrio entre fé e razão, entre a autonomia do homem e a sua mais completa submissão a Deus. Esses traços se manifestam de modo 
particular em Tomás de Aquino, uma das figuras dominantes deste período e um dos maiores filósofos e teólogos de todos os tempos. (MONDIN, 2013)

Pela Universidade de Nápoles, Tomás de Aquino foi introduzido nas obras de Aristóteles, Averróis e Maimônides, todos que influenciariam sua filosofia teológica. Estudou filosofia em Nápoles e depois em Paris, onde se dedicou ao ensino e ao estudo de questões filosóficas e teológicas. Mais tarde, estudou teologia em Colônia e, em Paris, tornou-se discípulo de Alberto Magno, que o "descobriu" e se impressionou com a sua inteligência. Por esse tempo foi apelidado de "boi mudo". Dele disse Alberto Magno: "Quando este boi mugir, o mundo inteiro ouvirá o seu mugido." Foi ordenado sacerdote com 1250, e começou logo a ensinar na Universidade de Paris em 1252, no reinado de Luís IX.

Foi em meados do século XIII que começou a escrever suas palestras e resumos, sendo que as suas duas principais obras, Summa theologica e Summa contra gentiles, sistematizaram o conhecimento teológico e filosófico. A partir delas, a igreja católica romana tem uma Teologia (conhecimento a partir da revelação) e uma Filosofia (conhecimento a partir da razão humana). Ambas se fundem em uma síntese definitiva: fé e razão, unidas em sua orientação comum que é Deus.

Origina-se o tomismo ${ }^{3}$ da percepção sensível do mundo, para, após, dela tirar, no plano abstrativo da inteligência, todo um conjunto consequente e harmonioso de teses. Bem define a filosofia de Tomás, o papa Leão XIII quando escreve na encíclica ${ }^{4}$ Aeterni Patris: "O Doutor Angélico buscou as conclusões filosóficas nas razões principais das coisas, que têm grandíssima extensão e conservam em seu seio o germe de quase infinitas verdades, para serem desenvolvidas em tempo oportuno e com abundantíssimo fruto pelos mestres dos tempos posteriores".

Se o tomismo admite entes de razão cuja realidade objetiva está tão somente na inteligência, os seres racionais nada mais são que ideias formuladas pela razão para que melhor se atinja a realidade existencial das coisas. Para este filósofo, em Deus o ser atinge a sua suprema perfeição.

Tomás de Aquino, não acreditava em um mundo das ideias e sob a influência do naturalismo aristotélico defenderá a existência de um mundo real, material. Esse mundo seria a criação divina - esta é uma das questões que surge ao seu tempo, a criação. Ele aponta a apreensão do divino através da verdade da razão que não pode ser negada pela verdade revelada da fé, ambas precisam ser idênticas, do contrário a fé ou a razão não foram adequadamente empreendidas. A teologia e a filosofia não se opõem. Fé e razão estão unidas em um único sentido: a perfeição, ou seja, o conhecimento de Deus.

A Escolástica chega ao ápice com Santo Tomás de Aquino (1221-1274), autor de uma poderosa síntese entre pensamento grego (Aristóteles, sobretudo, cujas obras começavam a estar disponíveis naqueles anos) e pensamento cristão que ainda hoje tem autoridade para ser indicado como insuperável e atual para enfrentar os problemas diante dos quais a humanidade se encontra. Aqui, falaremos dela somente no que se refere à ética e, infelizmente, sem poder fazer justiça à sua complexidade. (DEMÉTRIO, 2004)

Para Tomás de Aquino a verdade e o conhecimento também são alcançados através de um mestre interior, porém não há a intervenção de uma luz divina para que se dê esse conhecimento, ele já existe como

\footnotetext{
${ }^{3}$ Conjunto das doutrinas teológicas e filosóficas do pensador italiano Tomás de Aquino.

${ }^{4}$ Carta circular do papa abordando algum tema da doutrina católica.
} 
potencialidade no interior do ser e cabe a este descobri-lo através do aprendizado, do estudo, da educação religiosa e da pedagogia.

\section{A Ética Moral para Tomás de Aquino}

Na sua ética, São Tomás de Aquino parte do princípio da existência de Deus, porque nenhuma ética é possível sem uma metafísica qualquer; aliás este é o grande problema ético dos ateístas e a necessidade da transformação do ateísmo em naturalismo reflete a necessidade ética de uma metafísica, que na prática significa religião.

No plano filosófico a diferença fundamental entre o pensamento ético de Santo Tomás e o de Santo Agostinho nasce do fato de que o primeiro enquadra a própria reflexão na metafísica aristotélica e tenta mostrar como o naturalismo teológico Aristotélico pode se conciliar com o ideal de vida boa proposto pelo cristianismo. (DEMÉTRIO, 2004)

Para Tomás de Aquino existem duas espécies de mal: pena e culpa. A pena é a deficiência da forma ou de uma das suas partes, necessária para a integridade de algo. A culpa é dos males, que a providência ${ }^{5}$ tenta corrigir ou eliminar com a pena.

A culpa é o ato humano de escolha deliberada do mal; a culpa não é inconsciente: o ser humano com culpa sabe que a tem, através da consciência. Contudo, o ser humano é dotado de capacidade para distinguir o Bem e, naturalmente, tende para ele.

Tomás de Aquino dá prosseguimento à tradição das éticas eudaimonistas ao considerar a felicidade como sendo o fim último da atividade humana. Existe moral porque todos querem ser felizes. Também dá sequência à tradição das éticas teológicas iniciadas por Agostinho, pois aceita a ideia, defendida por este, de que só em Deus se pode encontrar a verdadeira meta que estamos procurando.

O critério supremo da moral, para o eudaimonismo, é a felicidade, de tal modo que uma ação é julgada moralmente elogiável ou reprovável, conforme ela seja ou não cumprida em vista da felicidade. Os expoentes máximos desse tipo de moral são Aristóteles e Tomás de Aquino. Segundo ambos os autores, toda ação está dirigida para um fim, mas isso não é suficiente para torná-la válida; isto acontece somente no caso em que o fim particular em vista do qual é feita esteja harmonizado com o fim último para o qual está orientado aquele que a cumpre. O fim último de cada ente constitui a sua realização completa, a qual é conseguida com o desenrolar, a pleno ritmo, daquela atividade que age em sua natureza específica. Do alcance deste fim último depende a sua felicidade. (MONDIN, 2013)

A felicidade perfeita para o homem não é possível nesta vida, mas em outra vida futura e definitiva. Enquanto não chegar esse momento, o tipo de felicidade de que mais se parece com aquela, segundo Tomás, é a que proporciona a contemplação da verdade. Deus não é só a fonte na qual o ser humano saciará sua sede mais radical, pois estabeleceu a lei eterna e dentro dela fixou os conteúdos gerais da moral como lei natural.

Para S. Tomás a contemplação possui um sentido eminentemente teológico: a única contemplação que pode exaurir todas as exigências do pensamento, e que por isso pode tornar repleta a alma de felicidade, é a contemplação de Deus. Para compreender perfeitamente o pensamento de $\mathrm{S}$. Tomás sobre esse ponto, é necessário, porém, fazer-se uma precisão: o conhecimento de Deus, no qual ele repõe a plena felicidade do homem, não é certamente aquele conhecimento analógico de Deus que a nossa mente pode

\footnotetext{
${ }^{5}$ É um termo utilizado na teologia que referenda ao um poder máximo, superintendência, devotado a vontade de Deus sobre todos os acontecimentos na vida dos seres humanos compreendidos no tempo.
} 
alcançar durante a vida presente. Nem o conhecimento metafísico mais alto pode bastar para nos fazer felizes, visto que a reflexão filosófica faz com que vejamos mais o que Deus não é do que o que ele é. (MONDIN, 2014)

Para Tomás então, é em Deus que reside a verdadeira felicidade. A felicidade humana, como também o conhecimento da felicidade, acontecem pela visão beatífica de Deus. A lei natural contém um princípio imperativo que deriva da própria noção do bem: "deve se fazer o bem e evitar o mal”. Esse preceito natural está dentro de nós, em forma de uma espécie de intuição ou "hábito que contém os preceitos da lei natural que recebe o nome de sindérese" (Summa theologica. I-II, q 94). A aplicação desses preceitos às circunstâncias concretas de cada ação é o que constitui a consciência.

A Ética Tomista ocupa-se então da ação humana que têm sua raiz na vontade livre. Dessa forma, Tomás apresenta os princípios norteadores da ação humana que são os princípios intrínsecos que são as virtudes e os princípios extrínsecos que são as leis.

A lei é regra e medida das ações e para desenvolver essa tarefa deve depender de uma fonte imutável: essa fonte pode ser apenas a razão, ao passo que a vontade é o instrumento de que a razão se serve para realizar suas determinações. Isso vale também para Deus: uma vez que Deus é a fonte do que é justo, negaria a si mesmo se violasse a ordem eterna de justiça que ele deu ao mundo. (DEMÉTRIO, 2004)

A Lex aeterna identifica a própria organização do universo como foi desejada por Deus na criação, e na qual todas as coisas têm seu lugar e seu fim determinado pela natureza. Tudo no universo está sujeito a essa lei. A lei eterna opera independentemente do fato de ser reconhecida ou não como fruto do projeto criador de Deus.

A Lex naturalis é a lei que se refere a criatura humana. Como parte da lex aeterna, ela determina a natureza do homem, como sendo uma determinação não passiva. A lex naturalis é uma participação ativa da lex aeterna, pois o traço distintivo do homem é a razão que lhe permite conhecer a lei natural. 0 princípio fundamental da lei natural é "faz o bem, evita o mal" que o homem é capaz de compreender graças à sindérese.

A Lex humana é o conjunto das leis positivas que especificam as prescrições gerais da lei natural e da lei eterna. A lei humana obriga somente quando as disposições são deduzidas da lei natural, ou pelo menos não contradizem. Quando a lei humana contradiz diretamente a lei divina, é que se torna absolutamente proibido observá-la.

\section{CONCLUSÕES}

Agostinho utilizando a herança antiga, aprofunda os conteúdos da concepção cristã do mundo. A ética de Agostinho é, pois, uma ética eudemonista e teleológica e a diferença em relação à grega é que a felicidade não consiste em bens do corpo e do espírito ou em ambos, mas no gozo de Deus, que é autêntico sumo bem. Ele formula o seu pensamento apontando para uma ética do amor e não da lei. Para Agostinho não basta agir segundo a lei, mas é preciso assim proceder com a intenção adequada, que deve ser a do amor e do desejo de se aperfeiçoar para se aproximar cada vez mais desse propósito. 
Tomás de Aquino utilizou a doutrina aristotélica como base para escrever suas obras que eram vistas com certo temor pela igreja católica romana, a qual tomava como base as obras de Agostinho, cujo embasamento é platônico. Sua intenção é utilizar a filosofia aristotélica como instrumento para transformar a teologia numa ciência autêntica e verdadeira. O tomismo, portanto, visa esclarecer a relação entre a verdade revelada e a filosofia, demonstrando que tais conceitos são distintos e harmônicos.

Nessa abordagem, Tomás de Aquino versa sobre a lei que, segundo ele, é uma ordem ou prescrição da razão para o bem comum, visando induzir gradualmente os homens à virtude e à beatitude, dirigir o saber humano segundo a ordem da justiça e conduzir os homens às observâncias dos preceitos. Mesmo que muitos não adotem, e também o próprio Direito, a ideia de uma lei eterna ou superior, nota-se que ainda hoje a intenção das leis é dirigir as ações humanas segundo uma ordem de justiça, para que haja observância das regras sociais estipuladas para uma boa convivência, chegando a um fim, que é a paz social.

É interessante perceber que tanto Agostinho como Tomás de Aquino, abordam as virtudes como elementos essenciais à conduta humana. Entretanto, para o mundo contemporâneo, falar de virtudes morais pode parecer algo ultrapassado, pois a razão moderna fez que esse tema caísse no esquecimento, como se a ele não pudesse ser atribuído a racionalidade que os modernos pretendem ter inventado. Todavia, assistimos, ultimamente, a várias tentativas de recuperação da noção de virtude como forma de dar inteligibilidade à vida ética.

\section{REFERÊNCIAS}

AGOSTINHO, S.. A cidade de Deus. 4 ed. Petrópolis: Vozes, 1990.

AGOSTINHO, S.. O livre-arbítrio. 3 ed. São Paulo: Paulus, 1995.

AgOSTINHO, S.. Confissões. São Paulo: Nova Cultural, 1996.

CARNEIRO, M. C.. Considerations on the idea of time in St. Augustine, Hume and Kant. Interface - Comunic., Saúde, Educ., Botucatu, v.8, n.15, p.221-32, 2004.

CAVALCANTE, T. M.; OLIVEIRA, T.. Intenção educacional da ética de Tomás de Aquino no contexto citadino no século XIII. Educ. rev., Belo Horizonte, v.28, n.2, 2012. DOI: http://doi.org/10.1590/S0102-46982012000200011

CORTINA, A.; MARTINEZ, E.. Ética. São Paulo: Loyola, 2005.

GIL, A. C.. Como elaborar projetos de pesquisa. 4 ed. São Paulo: Atlas, 2008.

MONDIN, B.. Curso de Filosofia. São Paulo: Paulus, 2013.

MONDIN, B.. Introdução à filosofia: problemas, sistemas, autores, obras. São Paulo: Paulus, 2014.

NERI, D.. Filosofia Moral: Manual Introdutivo. São Paulo: Loyola, 2004
NUNES, R.; STOELBEN, A.. Agostinho, Tomás, a filosofia e a educação. 2011.

OS PENSADORES. Santo Agostinho. São Paulo: Abril Cultura 1980.

PEREIRA, R. H. S.. Agostinho de Hipona: considerações sobre o mal e temas correlatos em De libero arbítrio. Veritas revista de filosofia, Porto Alegre, n.2, v.58, p.567-597, 2013. DOI: http://doi.org/10.15448/1984-6746.2013.3.12957

PÉREZ, R. G.. História básica da filosofia. São Paulo: Nerman, 1988.

PESSANHA, J. A. M.. Santo Agostinho (354-430): Vida e Obra. In: OS PENSADORES. Santo Agostinho. São Paulo: Abril Cultural 1980.

SILVA, C. E.. Elaboração de TCC e publicação de artigos: for starters. Aracaju: Sustenere Publishing, 2018.

SILVA, M. A. O.. Tomás de Aquino e a essência absolutamente considerada. Kriterion, Belo Horizonte, v.56 n.131, 2015. DOI: http://doi.org/10.1590/0100512X2015n13106mas

VAZ, H. C. L.. Escritos de filosofia IV: Introdução à ética filosófica 1.6 ed. São Paulo: Edições Loyola, 2012.

A CBPC - Companhia Brasileira de Produção Científica (CNPJ: 11.221.422/0001-03) detém os direitos materiais desta publicação. Os direitos referem-se à publicação do trabalho em qualquer parte do mundo, incluindo os direitos às renovações, expansões e disseminações da contribuição, bem como outros direitos subsidiários. Todos os trabalhos publicados eletronicamente poderão posteriormente ser publicados em coletâneas impressas sob coordenação da Cognitionis Publishing, da Companhia Brasileira de Produção Científica e seus parceiros autorizados. Os (as) autores (as) preservam os direitos autorais, mas não têm permissão para a publicação da contribuição em outro meio, impresso ou digital, em português ou em tradução. 